\title{
Component resolved diagnosis: when should it be used?
}

Olga Luengo ${ }^{1,2^{*}}$ and Victòria Cardona $a^{1,2}$

\begin{abstract}
The knowledge on molecular allergy diagnosis is continuously evolving. It is now time for the clinician to integrate this knowledge and use it when needed to improve the accuracy of diagnosis and thus provide more precise therapeutic and avoidance measures. This review does not intend to comprehensively analyze all the available allergen molecules, but to provide some practical clues on use and interpretation of molecular allergy diagnosis. The potential role of component resolved diagnosis in circumstances such as the indication of allergen immunotherapy, pollen polysensitization, food allergy, latex allergy or anaphylaxis, is assessed. Interpreting the information provided by molecular allergy diagnosis needs a structured approach. It is necessary to evaluate single positivities and negativities, but also to appraise "the big picture" with perspective.
\end{abstract}

Keywords: Molecular allergy, Component resolved diagnosis, Allergen molecules, Allergen microarray, Polysensitization, Immunotherapy

\section{Introduction}

Nearly 15 years after the concept of component-resolved diagnosis was first proposed [1], the amount of knowledge on the molecular allergy diagnosis is continuously evolving. Several comprehensive and extensive reviews on component resolved diagnosis (CRD) have been published, and their use and limitations in clinical practice proposed [2-4]. It is now time for the clinician to integrate this knowledge and use it when needed to improve the accuracy of diagnosis and thus provide more precise therapeutic and avoidance measures.

However, even after a thorough study of the literature the interpretation of molecular allergy diagnosis can initially seem very complex. So, there is an unmet need for educational programs on the use and interpretation of molecular diagnosis. Among other initiatives, our group has been developing a practical training program on molecular allergy diagnosis for the last four years with attendees from Spain and Portugal. With the WAOARIA-GALEN consensus on molecular diagnosis [4] as the framework, clinicians attending these workshops developed a proposal on "when to use CRD" in their

\footnotetext{
*Correspondence: oluengo@vhebron.net

${ }^{1}$ Allergy Section, Department of Internal Medicine, Hospital Vall d'Hebron, Barcelona, Spain

${ }^{2}$ Allergy Research Group, Institut de Recerca Vall d'Hebron, Barcelona, Spain
}

routine care that can be summarized as shown in Table 1, which has been used as a guide for this paper. This review does not intend to comprehensively analyze all the available allergen molecules, or all the specific aspects of food, respiratory, venom or latex allergy, but to provide some practical clues on use and interpretation of molecular allergy diagnosis.

\section{Indication of specific immunotherapy}

The first premise for the prescription of immunotherapy based on CRD is the assessment of IgE positivity to genuine versus cross-reactive allergens (Figures 1 and 2).

\section{Inhalant oligo/monosensitization}

Precise identification of relevant sensitizers in the case of pollen-allergic patient's mono or oligosensitized to pollens with no overlapping pollen season can be achieved by conventional diagnosis with complete pollen extracts. In most cases patients are sensitized to major pollen allergens (e.g. Ole e 1, Bet v 1, Phl p 1/Phl p 5 ), but this may not be the case in areas with high pollen loads, for example to olive pollen in the south of Spain, where Ole e 7 and Ole e 9, currently considered as minor allergens, can be the major sensitizers [5]. When prescribing specific immunotherapy in areas with high frequency of sensitization to "minor allergens", molecular diagnosis may 
Table 1 Proposals on when to use CRD

\begin{tabular}{|c|c|}
\hline \multicolumn{2}{|c|}{$\begin{array}{l}\text { Circumstances of potential increase of allergy diagnosis accuracy } \\
\text { by CRD }\end{array}$} \\
\hline \multirow{3}{*}{$\begin{array}{l}\text { - Indication of allergen } \\
\text { immunotherapy }\end{array}$} & o Inhalant oligo/monosensitization \\
\hline & o Pollen polysensitization \\
\hline & o Hymenoptera venom allergy \\
\hline \multirow[t]{3}{*}{ - Anaphylaxis } & $\begin{array}{l}\text { o Cofactor-enhanced food-dependent } \\
\text { anaphylaxis }\end{array}$ \\
\hline & o Delayed red meat anaphylaxis \\
\hline & o Idiopathic anaphylaxis \\
\hline \multicolumn{2}{|l|}{ - Latex allergy } \\
\hline - Polysensitization & o Pollen and plant food \\
\hline \multirow[t]{2}{*}{ • Food allergy } & o Risk assessment \\
\hline & $\begin{array}{l}\text { O Identification of unanticipated } \\
\text { allergen triggers }\end{array}$ \\
\hline
\end{tabular}

be of special interest, since commercial extracts for immunotherapy are well standardized only for major allergens. Thus, patients with sensitization to minor allergens alone may likely not receive sufficient amounts of allergen to achieve a successful outcome from allergen immunotherapy (AIT), or even worse, will experience adverse reactions when the concentrations of this minor allergens present in the extract are high [6].

Another scenario in which molecular allergy would help to decide the correct indication of AIT would be dog dander allergy. Unlike cat allergy, almost all attributable to sensitization to its major allergen Fel d 1, the sensitization profile in case of dog allergy is more heterogeneous [7]. In Spanish populations, Can $\mathrm{f} 5$ is a major allergen, with reported sensitizations of $70 \%$ of dog allergic patients [8]. In our series, Can f 1, 2 and 3 are minor allergens, while Can $\mathrm{f} 5$ is responsible for up to $67 \%$ of sensitizations and, importantly $37 \%$ of our patients are not sensitized either to Can $f 1,2$ or 3 but only to Can $f 5$ [9]. There is a high variability between commercial dog extracts regarding their allergen contents [10], and Can f 5 is poorly represented. It would not seem appropriate to indicate specific immunotherapy to dog extract in patients monosensitized to Can $\mathrm{f} 5$ until this (and possibly other) major allergen content is guaranteed in the therapeutic extract.

\section{Pollen polysensitization}

Unfortunately mono/oligosensitized patients are more and more scarce, at least in adults whose diagnostic complexity increases with polysensitization [11]. Although most studies on the relevance of CRD in complex pollen areas have been performed in the south of Europe, polysensitization to respiratory allergens is also seen in the north. This has been shown by data of the European Community Respiratory Health Survey (ECRHS) where $12.8 \%$ to $25.3 \%$ of patients were polysensitized [12]. This fact has important implications when considering the prescription of immunotherapy.

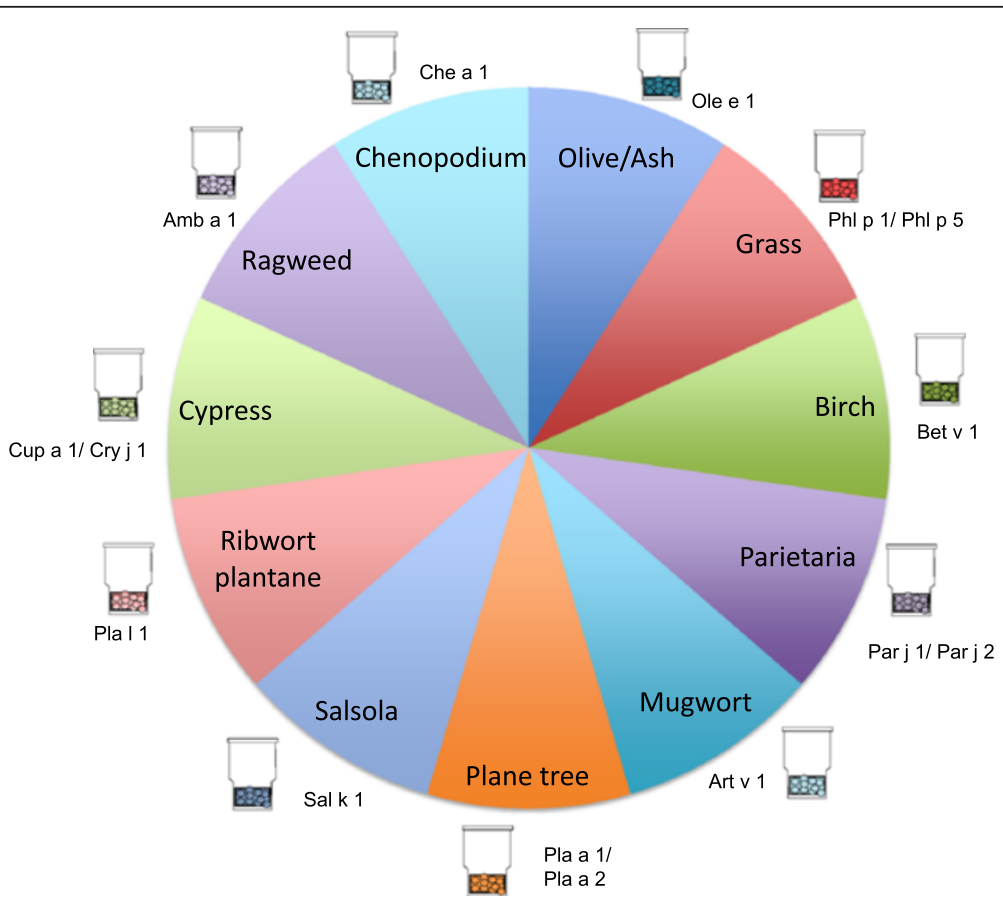

Figure 1 Pollen species-specific allergens. 


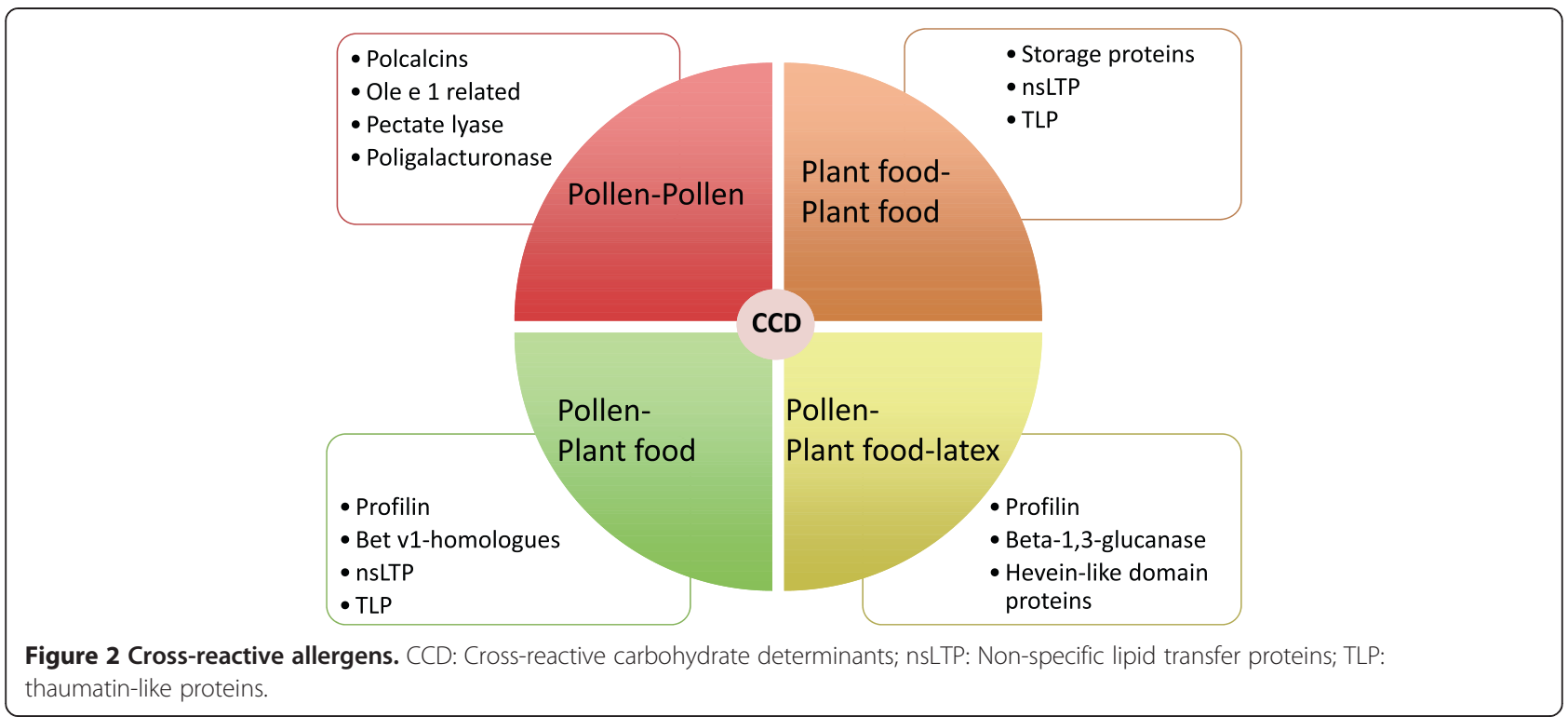

In recent large clinical trials, single-allergen immunotherapy with grass pollen extract has proved to be as safe and effective for that specific allergy both in polysensitized as in monosensitized patients [13,14], provided that the allergen extract administered matches the patient's most relevant sensitization.

CRD provides the information on patient specific allergen sensitization to drive the selection of the immunotherapy extract [15], conceptually "component-resolved treatment". AIT would be appropriately prescribed if sensitization to the species-specific allergens is confirmed, while in case of selective recognition of crossreactive allergens, like profilins or $\mathrm{CCD}$, the indication of AIT is arguable. Cross-reactive allergens seem to have limited clinical relevance and their content in AIT extracts is usually not quantified. Also, in the case of sensitization to the crude extract (SPT and/or positive sIgE), AIT indication would be arguable if all components are negative, since the extracts would be unlikely to contain the sensitizing molecule.

Proving the importance of a CRD-driven immunotherapy prescription, three prospective studies, including adult and pediatric population, have recently shown that the incorporation of CRD results alters initial AIT prescription in approximately half of the patients [16-18]. However, there is still a gap between the current possibility of using a predefined AIT preparation and the complexity of sensitization at the population level, since the patients SIgE profiles are highly heterogeneous depending on the geographical area and the allergen source $[19,20]$. Also, there is a need to adequately evaluate in prospective studies if CRD-guided patient selection results in improved efficacy of immunotherapy.
Since the first proposal of Valenta [1], few articles have been published on how to use CRD results for the optimal selection of immunotherapy. Very recently Douladiris et al. have proposed a comprehensive and practical algorithm regarding component-resolved diagnostic work-up for pollen AIT candidates in southern Europe [21].

\section{Hymenoptera venom immunotherapy}

Molecular diagnosis can also improve the selection of patients for hymenoptera venom immunotherapy (VIT). The diagnosis of hymenoptera venom allergy should be performed using non-glycosilated allergens to avoid false-positive sIgE results due to cross-reactive carbohydrates. Commercially available species-specific major allergens without CCD include Api m 1 from bee venom (phospholipase), Ves $\mathrm{v} 1$ (phospholipase) and Ves $\mathrm{v} 5$ (antigen 5) from Vespula venom and Pol d 5 (antigen 5) from Polistes dominulus venom.

Antigen 5 and phospholipase of both Vespula vulgaris and Polistes dominulus help discriminate between true genuine allergy and serological cross-reactivity in cases of double positivity to traditional sIgE and venom skin tests to both vespids [22]. Ebo et al. [23] also propose the use of CRD with rVes $v 1$ and rVes $v 5$ in patients with double-positive sIgE to yellow jacket and honey bee venom, discrepant sIgE and venom skin test results, as well as patients with negative traditional sIgE and skin tests. Müller et al. [24] recommend the indication of VIT to both bee and Vespula venoms in patients with double positivity of sIgE to whole venoms, and sIgE to Api $\mathrm{m} 1$, Ves $\mathrm{v} 1$ and Ves $\mathrm{v} 5$. If only positive to Api $\mathrm{m}$ 1 , VIT should be indicated only with bee venom. In 
patients with sIgE only to Ves $\mathrm{v} 1$ and Ves $\mathrm{v} 5$, VIT with Vespula venom would be certainly indicated. rVes $\mathrm{v} 5$ has also proved to facilitate diagnosis of hymenoptera venom allergy in patients with negative sIgE to wasp venom [25]. In the case of honeybee venom allergy it has been recently published that a broader panel of CCD-free honey bee venom allergens, including rApi $\mathrm{m}$ 2, rApi $\mathrm{m} \mathrm{3,} \mathrm{nApi} \mathrm{m} \mathrm{4,} \mathrm{rApi} \mathrm{m}$ 5, and rApi $\mathrm{m}$ 10, improves diagnostic sensitivity compared with use of rApi m 1 alone [26].

\section{Anaphylaxis}

\section{Cofactor-enhanced food-dependent anaphylaxis}

Epidemiological data show that cofactors (exercise, NSAIDs, alcohol, etc.) are relevant in up to $39 \%$ of all fooddependent anaphylactic reactions in adults [27]. Wheat dependent exercise-induced anaphylaxis (WDEIA) is the best characterized of these syndromes, classically related to omega-5-gliadin sensitization. Recently it has been reported that, at least in the Mediterranean population nsLTP accounts for the majority of cofactor-enhanced food allergy (CEFA) $[28,29]$ mainly related with vegetables, nuts and cereals. Even in cases of WDEIA reactions, positivity to nsLTP in the absence of omega-5-gliadin sensitization has been reported [30]. Therefore, at least in southern Europe, patients with a history consistent with CEFA anaphylactic reactions should be tested for SIgE to nsLTP (mainly Pru p 3, but also to Tri a 14) and to omega-5-gliadin. Other underlying sensitizations may be relevant in some populations.

\section{Red meat delayed anaphylaxis}

When evaluating a patient with a history of delayed onset anaphylaxis 3-6 h after ingestion of mammalian food products (e.g., beef and pork), sIgE against galactose- $\alpha-$ 1,3 -galactose $(\alpha$-gal) should be performed [31]. Before the identification of the allergen responsible for this syndrome, because of the delay of symptoms after ingestion of meat products, the frequent negative SPT responses and the good tolerance to other meats like turkey, these types of anaphylaxis have been wrongly classified as idiopathic [32]. It has been suggested that tick bites are the cause of IgE antibody responses to $\alpha$-gal and it is recommended to reassess sIgE levels every 8 to 12 months as they tend to decrease over time, and some patients have been able to tolerate mammalian meat again after avoiding additional tick bites for 1 to 2 years [33].

\section{Idiopathic anaphylaxis}

Although idiopathic anaphylaxis involves a small proportion of patients with anaphylaxis, the clinical implications are highly significant. The inability to identify a cause prevents from usual anaphylaxis interventions such as avoidance measures, specific education and modification of risk.

To date, only one study has addressed the question whether the ISAC allergy array would add diagnostic value in patients with idiopathic anaphylaxis. Heaps et al. [34] performed an ISAC-103 test (Thermo Fischer Scientific, Uppsala, Sweden) to 110 patients with a diagnosis of idiopathic anaphylaxis in UK and found new allergenic sensitizations in half of the patients studied, which in $20 \%$ of the cases were identified as the cause of the anaphylaxis with a high likelihood (although it was only reassessed in $50 \%$ of those patients). Omega-5-gliadin and shrimp allergens accounted for $45 \%$ of the previously unrecognized sensitizations. Other newly identified allergens related to the anaphylaxis were seed storage proteins, nsLTP and latex allergens. We must bear in mind that some molecules are poorly represented in allergen extracts, and therefore the sensitivity of conventional diagnostic tests (SPT, sIgE) will not allow a diagnosis.

Therefore, the performance of a multiplex CRD and sIgE to $\alpha$-gal, when available, would be very helpful in the assessment of idiopathic anaphylaxis. If positive, it may orientate on the triggering allergen; if negative, a non-IgE mediated mechanism underlying the anaphylaxis may be more likely.

\section{Latex allergy}

Correct identification of latex-sensitized patients with true latex allergy is of major importance as these patients have an increased risk for potentially severe reactions during medical procedures. On the other hand, identification of irrelevant latex-sensitization due to cross-reactive allergens would avoid a wrong diagnosis of latex allergy, prevent unnecessary latex-avoidance measures and reduce healthcare costs.

Latex allergens Hev b 1, Hev b 3, Hev b 5 and Hev b 6 are currently considered markers of genuine latex sensitization. On the other hand, studies on CRD of latex allergy have consistently shown that the majority of latex-sensitized persons, asymptomatic upon latex exposure, have a profilin sensitization with monosensitization to Hev b $8[35,36]$. Typically, these patients have a positive sIgE against latex, but are negative in SPT and do not show latex-specific symptoms upon contact with latex-containing material [37]. Haeberle et al. [38] and Quercia et al. [39] have reported that these patients can undergo major surgery in normal surgical setting without any consequences. Thus, Hev b 8 has been proposed as a marker of asymptomatic latex sensitization.

In the particular case of hymenoptera venom allergy with positive sIgE to latex, sensitization to CCD should be 


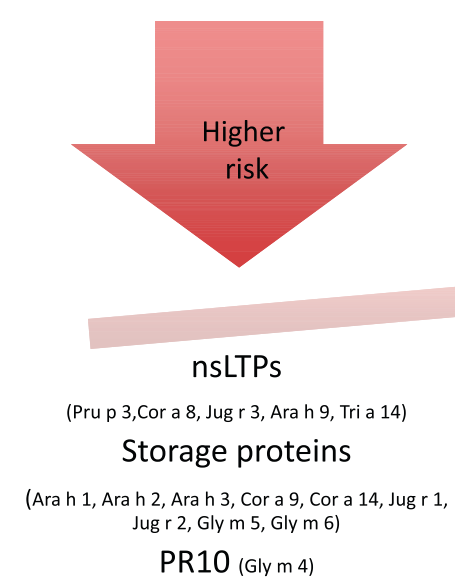

Wheat $\omega 5$-gliadin (Tri a 19)
Profilins (Cor a 2, Pru p 4, Mal d 4, Cuc m 2, Dau c 4)

PR-10 (Ara h 8, Cor a 1, Mal d 1, Cuc m1, Dau c 1)

CCD

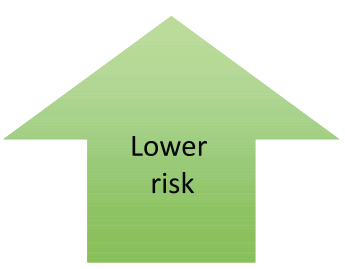

Figure 3 Allergens associated to higher versus lower risk of anaphylaxis. CCD: Cross-reactive carbohydrate determinants; nsLTP: Non-specific lipid transfer proteins.

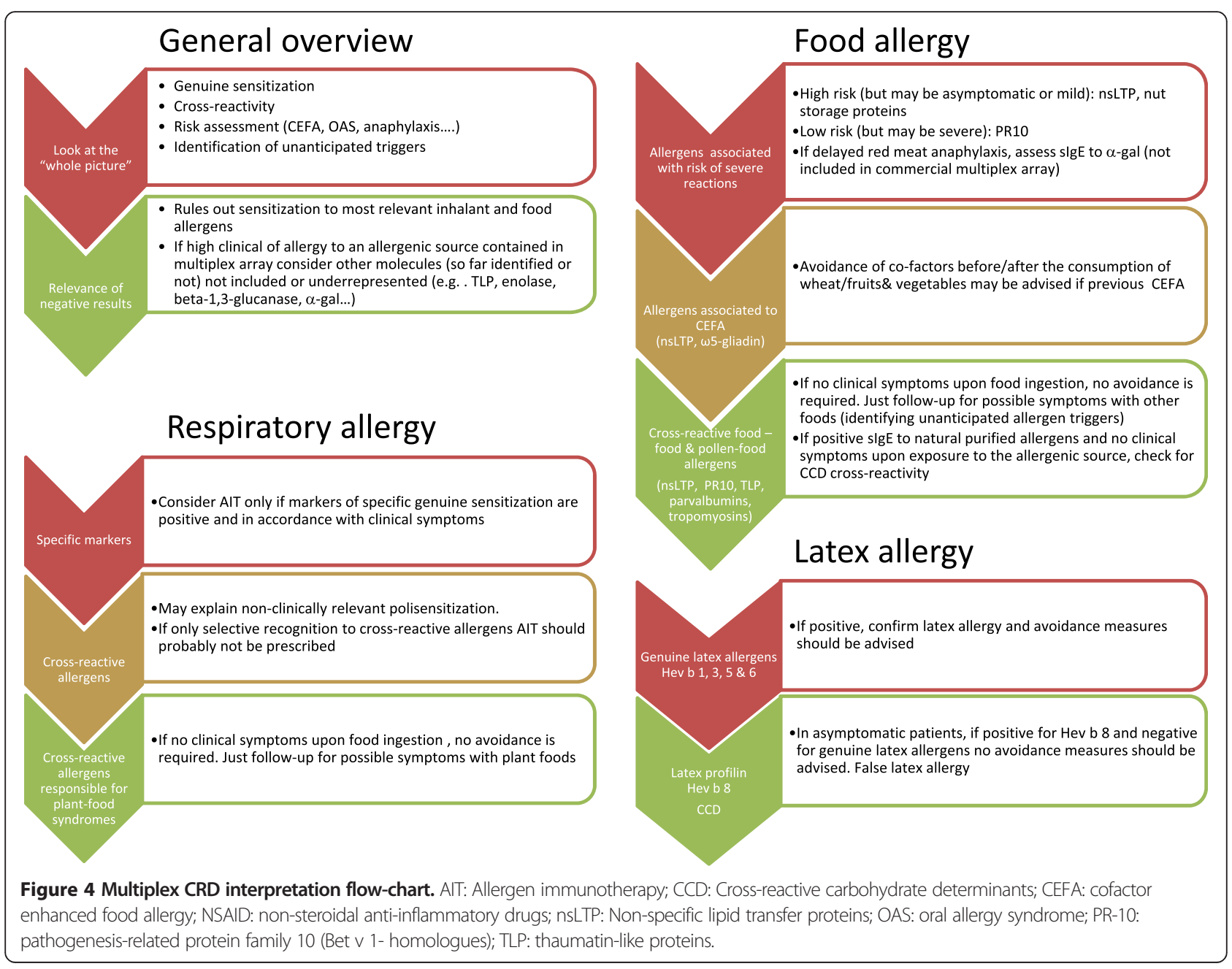




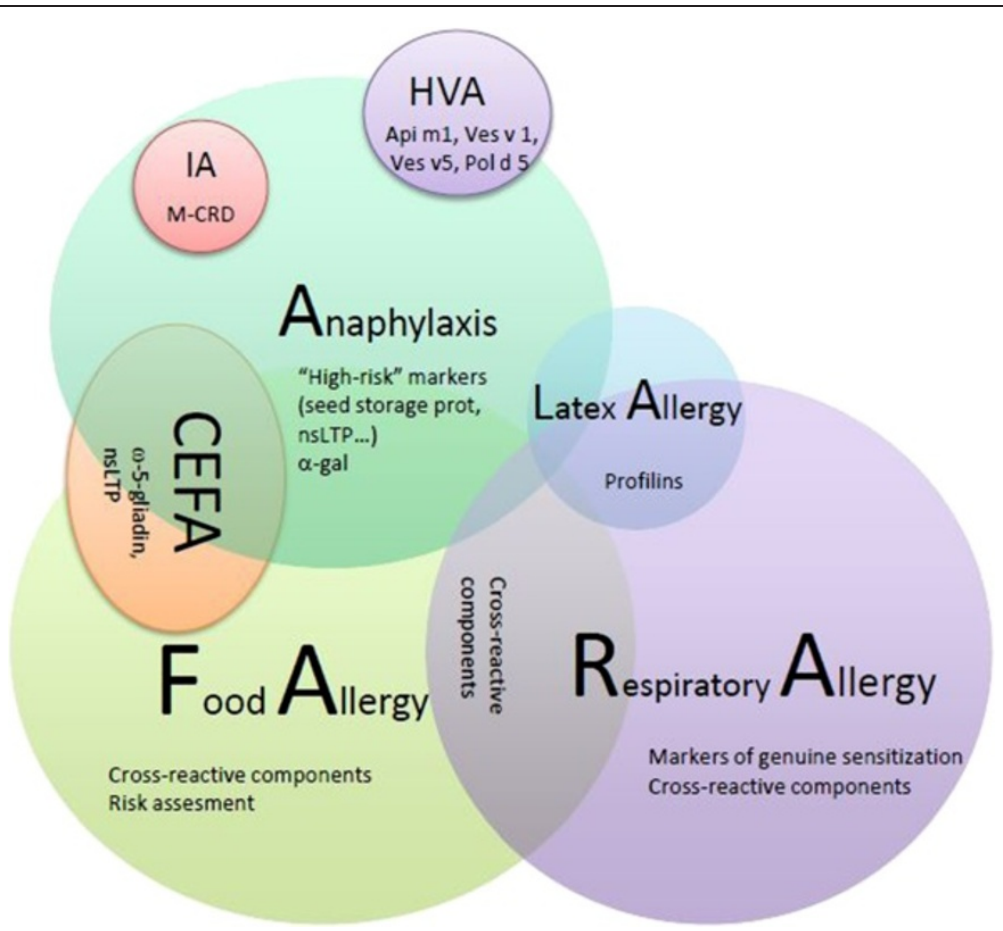

Figure 5 Hypothetical scheme representing the potential use of CRD. Represented by spheres are the allergic conditions in which molecular diagnosis may be of potential value, illustrating the potential overlap between different clinical reactions. Recommended components to be tested are listed; multiplexed CRD would be of special interest in idiopathic anaphylaxis and polysensitized patients. CEFA: cofactor-enhanced food allergy; HVA: hymenoptera venom allergy; IA: idiopathic anaphylaxis; M-CRD: multiplex CRD; nsLTP: non-specific lipid transfer proteins.

ruled out since insect venoms and latex share IgE-binding CCD responsible for non-clinically relevant positive serological test to commercial latex extract [40].

As a practical approach, in case of unequivocal clinical history of latex allergy with positive NRL-SPT and/or SIgE it may not be necessary to perform a CRD study since no association between allergens and severity of reactions has been identified so far.

Although cross-reactivity between several latex allergens (Hev b 5, Hev b 6, Hev b 7, Hev b 11, Hev b 13,...) and plant-food allergens has been described to explain the so called "latex-fruit syndrome", to date there are no riskassessment studies evaluating molecular sensitization profiles and clinical food-allergy in latex allergic patients.

\section{Polysensitization to inhalant and food allergens}

One of the biggest challenges for the allergist is to confront the patient with positive SPT to several pollen and food allergens. In this scenario CRD may be of major usefulness, improving the resolution of conventional diagnosis by adding information on the genuine primary sensitizers to distinguish them from sensitization due to cross-reactivity [41] (Figures 1 and 2). With regard to poly-pollen sensitization, this information may be relevant for prescribing AIT as discussed before.
Polysensitization to animal dander (cat, dog and horse) can in part be explained by cross-reactive lipocalins and albumins [7]. Can $\mathrm{f} 6$ (dog lipocalin) is a likely candidate for cross-species sensitization with cat (Fel d 4) and horse (Equ c 1) [42] with clinical relevance [43]. Serum albumin is also implicated in cross-reactivity in the socalled cat-pork syndrome, where patients developing a cat serum albumin IgE response react upon pork meat ingestion [44].

Allergic reactions to fruits and vegetables can result from a primary sensitization to food or to inhalant allergens. Usually, cross reactivity is attributable to labile allergens (e.g., PR-10 and profilins) and associated with mild oral reactions [45], while heat and proteolysisresistant allergens that primary sensitize through the oral route, are associated with systemic reactions in addition to local reactions (e.g. seed storage proteins and nsLTP) [2]. Sensitization to CCD in food or venoms does not have remarkable clinical relevance, and the primary sensitization may derive from either pollen or venoms. [46] Since purified native allergens may express carbohydrates (while recombinants do not), determination of sIgE to MUXF3 (a type of CCD) should be performed to rule out irrelevant sensitization to CCD in case of positive sIgE to purified native glycosilated allergens without clinical symptoms [47]. 


\section{Food allergy}

\section{Risk assessment}

Since the first study on CRD in apple allergy across Europe [48], where it was demonstrated that sensitization to apple nsLTP (Mal d 3) was associated with a 7 fold risk of anaphylaxis compared to sensitization apple Bet $\mathrm{v} 1$ homologue (Mal d 1), nsLTP have been considered markers of severe allergic reactions. However, studies on patterns of nsLTP sensitization in Mediterranean patients have shown that the clinical expression is variable, ranging from asymptomatic sensitization to severe anaphylaxis [49,50], possibly modulated by pollen allergen co-sensitization and the presence of cofactors [51]. A predictive pattern of clinical expression in nsLTP-sensitized patients has not yet been elucidated.

Bet $\mathrm{v} 1$ homologues are considered markers of mild allergic reactions to fruits and vegetables due to crossreactivity with birch pollen. However, although not frequent, some anaphylactic reactions to apple in patients sensitized to PR10-proteins have been reported [52]. In the particular case of soya allergy, Gly $\mathrm{m} 4$ (the Bet $\mathrm{v} 1$ related allergen in soya) has been related to severe, generalized symptoms [53].

Seed storage proteins from nuts and soya have been associated with higher risk of severe allergic reactions [54]. In the case of peanut, Ara $\mathrm{h} 2$ seems to be the best predictor of peanut allergy, reducing the need for peanut challenges by at least 50\% [55]. Altogether, Ara h 1, Ara h 2 and Ara h 3 have been associated with severe symptoms, although anaphylactic reactions have been described in patients negative for these allergens [56].

Sensitization to Cor a 9 and Cor a 14 have been reported to be highly specific for hazelnut allergic patients with objective symptoms in DBPCFCs and proposed as markers for a more severe hazelnut allergic phenotype [57]. Similarly, in patients with soybean allergy, Gly $\mathrm{m} 5$ and Gly $\mathrm{m} 6$ have been proposed as potential markers for severe allergic reactions [58].

Altogether, CRD may be a useful tool for stratifying patient's risk for severe reactions but it is important to bear in mind that the risk of developing anaphylaxis depends not only on the allergen sensitization pattern, but also on the avidity and affinity of immunoglobulins to bind the allergen, the route of application, characteristics of the allergen and the presence of cofactors [27]. Figure 3 depicts those allergens that have been associated to higher versus lower risk of anaphylaxis.

\section{Identification of unanticipated allergen triggers}

The sensitization profile also has major implications regarding the scope of types of plant foods that may trigger symptoms. Sensitization to seed storage proteins will limit allergic symptoms to nuts and occasionally to legumes [59], while sensitization to PR-10, nsLTP [60] or thaumatin-like proteins (TLP) [61] is frequently associated with symptoms with multiple fruits, vegetables, etc. However, currently there are no markers to predict the natural history; these patients should be followedup and informed about the potential future reactions, although there is no evidence to advice avoidance.

\section{When to use singleplex or multiplex CRD}

Single allergens for CRD can be either recombinant $(r)$ or natural purified (n) and sIgE can be measured either in singleplex or multiplex platforms. Depending on the aim of the CRD (guidance of AIT, polysensitization, latex allergy, etc.), the availability in each country and the complexity of the case, the clinician will choose one or the other. In general, for complex cases of multiple sensitizations to respiratory and food allergens as well as for idiopathic anaphylaxis study, a multiplex CRD should be performed. The clinician should be aware of benefits and pitfalls of molecular multiplex platforms before initiating a study. Multiplex assays allow up to 112 allergen assays in parallel with the use of very low serum quantities and no interference from very high total IgE but are less sensitive than singleplex assays and less appropriate for monitoring sensitization [4]. A guideline to help the allergy specialist to interpret multiplex molecular allergy diagnosis is proposed (Figure 4).

\section{Conclusions}

The vast information provided by molecular allergy needs a structured approach in order to be adequately interpreted. There is a need to evaluate single positivities and negativities, but also to appraise "the big picture" with perspective (Figure 5). When making decisions on this information, one has to bear in mind what is included in the tests and what is missing. It is needed that we understand that not all allergenic sources are present in the available arrays, but that the most important allergenic protein families are. This is relevant both when searching for a culprit allergen as when ruling out possible causes of certain reactions.

\section{Abbreviations}

AIT: Allergen immunotherapy; CCD: Cross-reactive carbohydrate

determinants; CEFA: Cofactor-enhanced food allergy; CRD: Component resolved diagnosis; MA: Molecular allergy; nsLTP: Non-specific lipid transfer proteins; OAS: Oral allergy syndrome; TLP: Thaumatin-like proteins.

\section{Competing interests}

The Allergy Research Group, to which OL and VC belong, receives research funds from Thermo Fischer Scientific, Spain.

\section{Author's contributions}

All authors have equally collaborated in the design and drafting of this review. All authors read and approved the final manuscript.

\section{Acknowledgements}

We thank our colleagues Moises Labrador and Mar Guilarte for fruitful discussions and a critical revision of the manuscript. 
Received: 19 June 2014 Accepted: 13 August 2014

Published: 8 September 2014

\section{References}

1. Valenta R, Lidholm J, Niederberger V, Hayek B, Kraft D, Grönlund H: The recombinant allergen-based concept of component-resolved diagnostics and immunotherapy (CRD and CRIT). Clin Exp Allergy 1999, 29:896-904.

2. Sastre J: Molecular diagnosis in allergy. Clin Exp Allergy 2010, 40:1442-1460.

3. Treudler R, Simon JC: Overview of component resolved diagnostics. Curr Allergy Asthma Rep 2013, 13:110-117.

4. Canonica GW, Ansotegui IJ, Pawankar R, Schmid-Grendelmeier P, van Hage M, Baena-Cagnani CE, Melioli G, Nunes C, Passalacqua G, Rosenwasser L, Sampson H, Sastre J, Bousquet J, Zuberbier T: A WAO - ARIA - GA²LEN consensus document on molecular-based allergy diagnostics. World Allergy Organ J 2013, 6:17.

5. Barber D, De La Torre F, Feo F, Florido F, Guardia P, Moreno C, Quiralte J, Lombardero M, Villalba M, Salcedo G, Rodríguez R: Understanding patient sensitization profiles in complex pollen areas: a molecular epidemiological study. Allergy 2008, 63:1550-1558.

6. Barber D, Moreno C, Ledesma A, Serrano P, Galán A, Villalba M, Guerra F, Lombardero M, Rodríguez R: Degree of olive pollen exposure and sensitization patterns. Clinical implications. J Investig Allergol Clin Immunol 2007, 17(Suppl 1):11-16.

7. Nilsson $\mathrm{OB}$, Van Hage M, Grönlund H: Mammalian-derived respiratory allergens - Implications for diagnosis and therapy of individuals allergic to furry animals. Methods 2014, 66:86-95.

8. Mattsson L, Lundgren T, Everberg H, Larsson HH, Lidholm J: Prostatic kallikrein: a new major dog allergen. J Allergy Clin Immunol 2009 123:362-368.

9. Basagaña M, Luengo O, Labrador-Horrillo M, Garriga T, Mattsson L, Lidholm J, Cardona V: Component resolved diagnosis of dog allergy. Allergy 2010, 65(Suppl. 92):683A.

10. Curin M, Reininger R, Swoboda I, Focke M, Valenta R, Spitzauer S: Skin prick test extracts for dog allergy diagnosis show considerable variations regarding the content of major and minor dog allergens. Int Arch Allergy Immunol 2011, 154:258-263.

11. Migueres M, Dávila I, Frati $F$, Azpeitia $A$, Jeanpetit $Y$, Lhéritier-barrand $M$ : Types of sensitization to aeroallergens: definitions, prevalences and impact on the diagnosis and treatment of allergic respiratory disease. Clin Transl Allergy 2014, 4:16.

12. Bousquet PJ, Castelli C, Daures JP, Heinrich J, Hooper R, Sunyer J, Wjst M, Jarvis D, Burney P: Assessment of allergen sensitization in a general population-based survey (European Community Respiratory Health Survey I). Ann Epidemiol 2010, 20:797-803.

13. Calderón MA, Cox L, Casale TB, Moingeon P, Demoly P: Multiple-allergen and single-allergen immunotherapy strategies in polysensitized patients: looking at the published evidence. J Allergy Clin Immunol 2012, 129:929-934.

14. Passalacqua $\mathrm{G}$ : The use of single versus multiple antigens in specific allergen immunotherapy for allergic rhinitis: review of the evidence. Curr Opin Allergy Clin Immunol 2014, 14:20-24.

15. Valenta R, Twaroch T, Swoboda I: Component-resolved diagnosis to optimize allergen-specific immunotherapy in the Mediterranean area. J Investig Allergol Clin Immunol 2007, 17(Suppl 1):36-40.

16. Sastre J, Landivar ME, Ruiz-García M, Andregnette-Rosigno MV, Mahillo I: How molecular diagnosis can change allergen-specific immunotherapy prescription in a complex pollen area. Allergy 2012, 67:709-711.

17. Letrán A, Espinazo M, Moreno F: Measurement of lgE to pollen allergen components is helpful in selecting patients for immunotherapy. Ann Allergy Asthma Immunol 2013, 111:295-297.

18. Stringari G, Tripodi S, Caffarelli C, Dondi A, Asero R, Di Rienzo Businco A, Bianchi A, Candelotti P, Ricci G, Bellini F, Maiello N, Miraglia Del Giudice M, Frediani T, Sodano S, Dello lacono I, Macrì F, Peparini I, Povesi Dascola C, Patria MF, Varin E, Peroni D, Comberiati P, Chini L, Moschese V, Lucarelli S, Bernardini R, Pingitore G, Pelosi U, Tosca M, Cirisano A, et al: The effect of component-resolved diagnosis on specific immunotherapy prescription in children with hay fever. J Allergy Clin Immunol 2014, 134:75-81.

19. Tripodi S, Frediani T, Lucarelli S, MacR F, Pingitore G, Di Rienzo Businco A, Dondi A, Pansa P, Ragusa G, Asero R, Faggian D, Plebani M, Matricardi PM: Molecular profiles of IgE to Phleum pratense in children with grass pollen allergy: Implications for specific immunotherapy. J Allergy Clin Immunol 2012, 129:834-839.
20. Darsow U, Brockow K, Pfab F, Jakob T, Petersson CJ, Borres MP, Ring J, Behrendt H, Huss-Marp J: Allergens. Heterogeneity of molecular sensitization profiles in grass pollen allergy-implications for immunotherapy? Clin Exp Allergy 2014, 44:778-786.

21. Douladiris N, Sawatianos S, Roumpedaki I, Skevaki C, Mitsias D, Papadopoulos NG: A molecular diagnostic algorithm to guide pollen immunotherapy in southern Europe: towards component-resolved management of allergic diseases. Int Arch Allergy Immunol 2013, 162:163-172.

22. Monsalve RI, Vega A, Marqués L, Miranda A, Fernández J, Soriano V, Cruz S, Domínguez-Noche C, Sánchez-Morillas L, Armisen-Gil M, Guspí R, Barber D: Component-resolved diagnosis of vespid venom-allergic individuals: Phospholipases and antigen $5 \mathrm{~s}$ are necessary to identify Vespula or Polistes sensitization. Allergy 2012, 67:528-536.

23. Ebo DG, Faber M, Sabato V, Leysen J, Bridts CH, De Clerck LS: Component-resolved diagnosis of wasp (yellow jacket) venom allergy. Clin Exp Allergy 2013, 43:255-261.

24. Müller U, Schmid-Grendelmeier $P$, Hausmann $O$, Helbling A: IgE to recombinant allergens Api $m$ 1, Ves $\vee 1$, and Ves $v 5$ distinguish double sensitization from crossreaction in venom allergy. Allergy 2012, 67:1069-1073.

25. Sturm GJ, Biló MB, Bonadonna P, Hemmer W, Caruso B, Bokanovic D, Aberer $W$ : Ves $\vee 5$ can establish the diagnosis in patients without detectable specific IgE to wasp venom and a possible north-south difference in Api m 1 sensitization in Europe. J Allergy Clin Immunol 2012, 130:817.

26. Köhler J, Blank S, Müller S, Bantleon F, Frick M, Huss-Marp J, Lidholm J, Spillner $\mathrm{E}$, Jakob T: Component resolution reveals additional major allergens in patients with honeybee venom allergy. J Allergy Clin Immunol 2014, 133:1383-1389.

27. Wölbing F, Biedermann T: Anaphylaxis: Opportunities of stratified medicine for diagnosis and risk assessment. Allergy 2013, 68:1499-1508.

28. Cardona V, Luengo O, Garriga T, Labrador-Horrillo M, Sala-Cunill A, Izquierdo A, Soto L, Guilarte M: Co-factor-enhanced food allergy. Allergy 2012, 67:1316-1318.

29. Romano A, Scala E, Rumi G, Gaeta F, Caruso C, Alonzi C, Maggioletti M, Ferrara R, Palazzo P, Palmieri V, Zeppilli P, Mari A: Lipid transfer proteins: the most frequent sensitizer in Italian subjects with food-dependent exercise-induced anaphylaxis. Clin Exp Allergy 2012, 42:1643-1653.

30. Pastorello EA, Farioli L, Stafylaraki C, Scibilia J, Mirone C, Pravettoni V, Ottolenghi Al, Conio S, Mascheri A, Losappio L, Capocchi A, Fontanini D, De Giacomo C: Wheat-dependent exercise-induced anaphylaxis caused by a lipid transfer protein and not by $\omega-5$ gliadin. Ann Allergy Asthma Immunol 2014, 112:386-387. e1.

31. Commins SP, Platts-Mills TA: Anaphylaxis syndromes related to a new mammalian cross-reactive carbohydrate determinant. J Allergy Clin Immunol 2009, 124:652-657.

32. Tripathi A, Commins SP, Heymann PW, Platts-Mills TA: Delayed anaphylaxis to red meat masquerading as idiopathic anaphylaxis. J Allergy Clin Immunol Pract 2014, 2:259-265

33. Berg EA, Platts-Mills TA, Commins SP: Drug allergens and food-the cetuximab and galactose-alpha-1,3-galactose story. Ann Allergy Asthma Immunol 2014, 112:97-101.

34. Heaps A, Carter S, Selwood C, Moody M, Unsworth J, Deacock S, Sumar N, Bansal A, Hayman G, El-Shanawany T, Williams P, Kaminski E, Jolles S: The utility of the ISAC Allergen Array in the investigation of Idiopathic Anaphylaxis. Clin Exp Immunol 2014, 177:483-490.

35. Ott H, Schröder C, Raulf-Heimsoth M, Mahler V, Ocklenburg C, Merk HF, Baron JM: Microarrays of recombinant Hevea brasiliensis proteins: a novel tool for the component-resolved diagnosis of natural rubber latex allergy. J Investig Allergol Clin Immunol 2010, 20:129-138.

36. Ebo DG, Hagendorens MM, De Knop KJ, Verweij MM, Bridts CH, De Clerck LS, Stevens WJ: Component-resolved diagnosis from latex allergy by microarray. Clin Exp Allergy 2010, 40:348-358.

37. Schuler S, Ferrari G, Schmid-Grendelmeier P, Harr T: Microarray-based component-resolved diagnosis of latex allergy: isolated IgE-mediated sensitization to latexprofilin Hev b8 may act as confounder. Clin Trans/ Allergy 2013, 3:11.

38. Haeberle HA, Lupic D, Midoro-Horiuti T, Kiefer RT, Schroeder TH, Unertl K, Dieterich $\mathrm{HJ}$ : Role of cross-allergies to latex in clinical routine of anesthesia. J Clin Anesth 2003, 15:495-504.

39. Quercia O, Stefanini GF, Scardovi A, Asero R: Patients monosensitised to Hev b 8 (Hevea brasiliensis latex profilin) may safely undergo major surgery in a normal (non-latex safe) environment. Eur Ann Allergy Clin Immunol 2009, 41:112-116. 
40. Mahler V, Gutgesell C, Valenta R, Fuchs T: Natural rubber latex and hymenoptera venoms share ImmunoglobinE-epitopes accounting for cross-reactive carbohydrate determinants. Clin Exp Allergy 2006, 36:1446-1456.

41. Passalacqua G, Melioli G, Bonifazi F, Bonini S, Maggi E, Senna G, Triggiani M, Nettis E, Rossi RE, Vacca A, Canonica GW: The additional values of microarray allergen assay in the management of polysensitized patients with respiratory allergy. Allergy 2013, 68:1029-1033.

42. Nilsson OB, Binnmyr J, Zoltowska A, Saarne T, Van Hage M, Grönlund H: Characterization of the dog lipocalin allergen Can $\mathrm{f} 6$ : the role in cross-reactivity with cat and horse. Allergy Eur J Allergy Clin Immunol 2012, 67:751-757.

43. Jakob T, Hilger C, Hentges F: Clinical relevance of sensitization to cross-reactive lipocalin Can f 6. Allergy 2013, 68:690-691.

44. Posthumus J, James HR, Lane CJ, Matos LA, Platts-Mills TAE, Commins SP: Initial description of pork-cat syndrome in the United States. J Allergy Clin Immunol 2013, 131:923-925.

45. Katelaris $\mathrm{CH}$ : Food allergy and oral allergy or pollen-food syndrome. Curr Opin Allergy Clin Immunol 2010, 10:246-251.

46. Ebo DG, Hagendorens MM, Bridts CH, De Clerck LS, Stevens WJ: Sensitization to cross-reactive carbohydrate determinants and the ubiquitous protein profilin: Mimickers of allergy. Clin Exp Allergy 2004, 34:137-144.

47. Villalta D, Conte M, Asero R, Da Re M, Stella S, Martelli P: Isolated lgE reactivity to native walnut vicilin-like protein ( $n$ Jug $r$ 2) on ISAC microarray is due to cross-reactive carbohydrate epitopes. Clin Chem Lab Med 2013, 51:1991-1995.

48. Fernández-Rivas M, Bolhaar S, González-Mancebo E, Asero R, van Leeuwen A, Bohle B, Ma Y, Ebner C, Rigby N, Sancho Al, Miles S, Zuidmeer L, Knulst A, Breiteneder H, Mills C, Hoffmann-Sommergruber K, van Ree R: Apple allergy across Europe: How allergen sensitization profiles determine the clinical expression of allergies to plant foods. J Allergy Clin Immunol 2006, 118:481-488.

49. Pascal M, Muñoz-Cano R, Reina Z, Palacín A, Vilella R, Picado C, Juan M Sánchez-López J, Rueda M, Salcedo G, Valero A, Yagüe J, Bartra J, Palacı A: Lipid transfer protein syndrome: Clinical pattern, cofactor effect and profile of molecular sensitization to plant-foods and pollens. Clin Exp Allergy 2012, 42:1529-1539.

50. Soto L, Luengo O, Labrador-Horrillo M, Sala-Cunill A, Guilarte M, Cardona V: Recognition pattern to individual allergens in pollen allergic patients sensitised to lipid transfer proteins. Allergy 2012, 67(Suppl. 96):541A.

51. Asero R, Pravettoni $V$ : Anaphylaxis to plant-foods and pollen allergens in patients with lipid transfer protein syndrome. Curr Opin Allergy Clin Immunol 2013, 13:379-385

52. Röseler S, Balakirski G, Plange J, Wurpts G, Baron JM, Megahed M, Merk HF: Anaphylaxis to PR-10 proteins (Bet v1 homologues). Hautarzt 2013, 64:890-892.

53. Berneder M, Bublin M, Hoffmann-Sommergruber K, Hawranek T, Lang R: Allergen chip diagnosis for soy-allergic patients: Gly $\mathrm{m} 4$ as a marker for severe food-allergic reactions to soy. Int Arch Allergy Immunol 2013, 161:229-233.

54. Nicolaou N, Custovic A: Molecular diagnosis of peanut and legume allergy. Curr Opin Allergy Clin Immunol 2011, 11:222-228.

55. Klemans RJB, Otte D, Knol M, Knol EF, Meijer Y, Gmelig-Meyling FHJ, Bruijnzeel-Koomen CAFM, Knulst AC, Pasmans SGMA: The diagnostic value of specific lgE to Ara $\mathrm{h} 2$ to predict peanut allergy in children is comparable to a validated and updated diagnostic prediction model. J Allergy Clin Immunol 2013, 131:157-163.

56. Sicherer SH, Sampson HA: Food allergy: Epidemiology, pathogenesis, diagnosis, and treatment. J Allergy Clin Immunol 2014, 133:291-307.

57. Masthoff LN, Mattsson L, Zuidmeer-Jongejan L, Lidholm J, Andersson K, Akkerdaas JH, Versteeg SA, Garino C, Meijer Y, Kentie P, Versluis A, Den Hartog Jager CF, Bruijnzeel-Koomen CAFM, Knulst AC, Van Ree R, Van Hoffen E, Pasmans SGMA: Sensitization to Cor a 9 and Cor a 14 is highly specific for a hazelnut allergy with objective symptoms in Dutch children and adults. J Allergy Clin Immunol 2013, 132:393-399.

58. Holzhauser T, Wackermann O, Ballmer-Weber BK, Bindslev-Jensen C, Scibilia J, Perono-Garoffo L, Utsumi S, Poulsen LK, Vieths S: Soybean (Glycine max) allergy in Europe: Gly m 5 (beta-conglycinin) and Gly $\mathrm{m} 6$ (glycinin) are potential diagnostic markers for severe allergic reactions to soy. J Allergy Clin Immunol 2009, 123:452-458.
59. Bublin M, Breiteneder $\mathrm{H}$ : Cross-Reactivity of Peanut Allergens. Curr Allergy Asthma Rep 2014, 14:426.

60. Egger M, Hauser M, Mari A, Ferreira F, Gadermaier G: The role of lipid transfer proteins in allergic diseases. Curr Allergy Asthma Rep 2010, 10:326-335

61. Palacín A, Rivas LA, Gómez-Casado C, Aguirre J, Tordesillas L, Bartra J, Blanco C, Carrillo T, Cuesta-Herranz J, Bonny JAC, Flores E, García-Alvarez-Eire MG, García-Nuñez I, Fernández FJ, Gamboa P, Muñoz R, Sánchez-Monge R, Torres M, Losada SV, Villalba M, Vega F, Parro V, Blanca M, Salcedo G, Díaz-Perales A: The involvement of thaumatin-like proteins in plant food cross-reactivity: a multicenter study using a specific protein microarray. PLoS One 2012, 7:e44088.

doi:10.1186/2045-7022-4-28

Cite this article as: Luengo and Cardona: Component resolved diagnosis: when should it be used?. Clinical and Translational Allergy 2014 4:28.

\section{Submit your next manuscript to BioMed Central and take full advantage of:}

- Convenient online submission

- Thorough peer review

- No space constraints or color figure charges

- Immediate publication on acceptance

- Inclusion in PubMed, CAS, Scopus and Google Scholar

- Research which is freely available for redistribution 